\title{
Ciclos e letramento na fase inicial do ensino fundamental*
}

\author{
Creso Franco \\ Pontifícia Universidade Católica do Rio de Janeiro, Departamento de Educação
}

\section{Introdução}

No Brasil, alternativas à organização da escolarização em séries têm sido formuladas e implementadas desde longa data (Fernandes, 2000; Mainardes, 2001; Fernandes \& Franco, 2001; Barreto \& Mitrulis, 2001; Sousa \& Alavarse, 2003). No entanto, a descrição espacial da implantação de ciclos, a evolução temporal da implantação desta forma de organização da escolarização e a repercussão da política de ciclos sobre o nível de letramento de crianças e jovens brasileiros ainda são bastante precárias. O presente trabalho tem como objetivo preencher uma pequena parcela das lacunas acima mencionadas. Mais especificamente, pretendo:

a) apresentar as fontes a partir das quais é viável mensurar a prevalência da organização da escolarização em ciclos no ensino fundamental

* Trabalho apresentado no Grupo de Trabalho Alfabetização, Leitura e Escrita, durante a $26^{\mathrm{a}}$ Reunião Anual da ANPEd, realizada em Poços de Caldas, MG, de 5 a 8 de outubro de 2003. brasileiro e discutir abordagens que possibilitem superar os problemas metodológicos presentes em vários levantamentos que fazem uso dessas fontes;

b) usar algumas das fontes disponíveis para descrever o estado recente das políticas implantadas nas redes estaduais e nas redes municipais das capitais brasileiras no que se refere a ciclos nas etapas iniciais do ensino fundamental;

c) discutir as potencialidades e limitações das pesquisas quantitativas que procuraram avaliar a repercussão de ciclos na educação brasileira.

Finalizo esta introdução indicando que na maior parte deste trabalho usarei a expressão "organização da escolarização em ciclos" no sentido genérico com que o termo aparece na Lei de Diretrizes e Bases da Educação. Estou ciente de que há muito interesse em identificar as diferenças entre diversas propostas de ciclo. No entanto, tenho percebido que, freqüentemente, o aguçamento deste interesse tem redundado na subestimação da tarefa de mapear, ainda que de modo genérico, a presença de ciclos na educação bra- 
sileira. Àqueles particularmente interessados nas diferenças entre diversas concepções de ciclo, peço paciência: espero que um pouco de quantificação sobre a situação contribua para melhor qualificação do debate sobre ciclos.

\section{Mensurando a presença de ciclos: fontes e dificuldades metodológicas}

A consolidação das experiências com ciclos básicos de alfabetização da década de 1980 redundou, na década de 1990, em propostas de sua extensão para etapas ulteriores do ensino fundamental (Mainardes, 2001). Com o intuito de quantificar a presença de ciclos na educação brasileira, o Censo Escolar de 1999 incluiu duas perguntas sobre o assunto e manteve-as nos questionários dos anos subseqüentes. A primeira pergunta pedia que se especificasse como se organiza o ensino na escola, incluindo-se como opção de resposta as opções por ciclos e séries e permitindo que, quando apropriado, ambas as opções fossem assinaladas. A segunda deveria ser respondida apenas em escolas que possuíam ciclos, e solicitava informação sobre o número de ciclos existentes e a duração de cada um deles. Há consenso entre os usuários do Censo Escolar quanto à dificuldade da segunda pergunta para os respondentes, o que tem inviabilizado sua utilização (Ferrão, Beltrão \& Santos, 2002). Já a primeira pergunta inserida tem funcionado bem, permitindo acompanhar, desde 1999, a adesão das escolas a diferentes formas de organização da escolarização. No entanto, as tabulações obtidas a partir dos dados do Censo Escolar podem gerar controvérsias. Um exemplo recente é o do boletim eletrônico do Instituto Nacional de Estudos e Pesquisas Educacionais Anísio Teixeira (INEP), de 17/9/ 2003, em que se lia:

Taxa representativa da matrícula nos ciclos é menor do que a de 1999: [de acordo com o censo escolar de 2002] o sistema de Ciclos de Aprendizagem abrange 20,9\% das matrículas do ensino fundamental do País. [...] a taxa representativa da matrícula nos ciclos é menor do que a regis- trada em 1999, quando o INEP fez o primeiro levantamento sobre o assunto. Naquele ano, $23 \%$ dos alunos estavam em estabelecimentos de ensino que mantinham esse sistema. Apesar de sua redução, o sistema de ciclos recebe apoio de vários especialistas em educação, como os professores Lisete Arelaro e Vitor Henrique Paro, da Universidade de São Paulo. ${ }^{1}$

Embora não tenha reparos aos percentuais divulgados, gostaria de sublinhar que os números não indicam a redução de ciclos como forma de organização do ensino fundamental. Inicialmente, deve ser considerado que, se a adesão das redes de ensino ao sistema de ciclos ficasse inalterada, seria observada a diminuição do percentual de matrícula de alunos em escolas organizadas em ciclos. Para entender a razão disso, basta considerar que, muito embora tenhamos cerca de 27 milhões de jovens na faixa etária entre 7 e 14 anos, a demanda por matrículas em 1999 era de cerca de 36 milhões de vagas em 1999 e de cerca de 35 milhões em 2002. Os vários milhões adicionais (9 milhões em 1999 e 8 milhões em 2002) estão relacionados à existência de distorção idade-série; e a diminuição do adicional de 1999 para 2002 deve-se exatamente à melhora do fluxo escolar, parcialmente relacionada à existência de ciclos. É justamente onde há mais organização da educação em ciclos que a matrícula no ensino fundamental mais diminuiu, e onde mais tem aumentado a frequiência ao ensino médio. Por isso, a adesão de redes escolares à organização em ciclos é mais bem representada pelo percentual de escolas - e não de alunos - que se organizam nas diversas formas. A Tabela 1 esclarece a situação, mostrando ligeiro aumento no percentual de escolas organizadas em ciclo no período de 1999-2002.

A despeito do pequeno aumento de 1999 para 2002, registre-se que a grande maioria das escolas ainda se organiza de modo seriado. Note-se também que o fato de o percentual de alunos matriculados em

${ }^{1}$ Disponível em: <http://www.inep.gov.br/imprensa/noticias/censo/escolar/news03_07.htm>. Acesso em: 17/09/2003. 
escolas organizadas em séries ser cerca da metade do percentual de alunos matriculados em escolas organizadas em ciclos é indicativo de que o tamanho médio das escolas organizadas em ciclos é maior do que o das organizadas em séries. Observe-se ainda que há escolas nas quais nem todo o ensino fundamental está organizado em ciclos ou em séries. $\mathrm{Na}$ classificação do INEP, essas são as escolas organizadas em série $e$ ciclos. Nessas escolas, o arranjo mais típico é a existência de ciclo no início do ensino fundamental e de séries em estágios posteriores. Como é mais provável que, com o passar do tempo, escolas que só ofereciam o início da escolarização passem a oferecer todo o ensino fundamental do que o contrário (isto é, escolas que ofereciam todo o ensino fundamental passarem a oferecer apenas os estágios iniciais do ensino fundamental), o real crescimento percentual da organização em ciclos pode ser maior do que a diferença expressa na Tabela 1.

Tabela 1 - Escolas do ensino fundamental organizadas em série ou em ciclos (\%)

\begin{tabular}{cccc}
\hline $\begin{array}{c}\text { Ano/Forma de } \\
\text { Organização } \rightarrow\end{array}$ & $\begin{array}{c}\text { Unicamente } \\
\text { Ciclos }\end{array}$ & $\begin{array}{c}\text { Unicamente } \\
\text { Séries }\end{array}$ & $\begin{array}{c}\text { Séries e } \\
\text { Ciclos }\end{array}$ \\
\hline 1999 & 10,0 & 82,4 & 7,6 \\
2002 & 10,9 & 80,6 & 8,5 \\
\hline
\end{tabular}

Fonte: INEP, Censo Escolar dos anos mencionados.

No ano de 2001, o questionário do Sistema de Avaliação da Educação Básica (SAEB) indagou sobre como se organizava o ensino ministrado aos alunos do ensino fundamental testados por ele $\left(4^{\mathrm{a}}\right.$ e $8^{\mathrm{a}}$ série ou seus equivalentes, quando organizado em ciclos). O questionário incluía ainda a pergunta sobre o número de ciclos existentes na escola e sua duração. Mais uma vez, esta segunda pergunta funcionou mal. No entanto, a primeira pergunta apurou adequadamente a forma de organização de escolarização dos alunos que completavam a primeira metade do ensino fundamental, o que viabiliza uma fonte adicional de informação sobre a organização da escolarização. Mais à frente, usarei os dados do SAEB 2001 para investigar até que ponto estados e grandes municípios brasileiros fazem uso da organização da escolarização em ciclos na parte inicial do ensino fundamental. Antes disso, é relevante trazer algumas evidências sobre a gravidade de alguns problemas ainda presentes na parte inicial do ensino fundamental brasileiro.

\section{O estágio inicial do ensino fundamental}

Ao longo dos últimos anos, os indicadores educacionais brasileiros apresentaram melhoras significativas, com destaque para o número médio de anos de escolaridade da população brasileira, para a taxa de escolarização líquida da população brasileira entre 7 e 14 anos e para a expansão do ensino médio, como mostrado nas Tabelas 2 e 3 e no Gráfico 1.

Tabela 2 - Evolução da escolaridade média da população brasileira de 25 anos ou mais

\begin{tabular}{cccccc}
\hline Ano & 1981 & 1990 & 1995 & 1998 & 2001 \\
\hline $\begin{array}{c}\text { Número médio de anos } \\
\text { de escolaridade }\end{array}$ & 3,8 & 4,9 & 5,2 & 5,6 & 6,0 \\
\hline
\end{tabular}

Fonte: PNAD, preparação do Instituto de Estudos do Trabalho e Sociedade, nos anos referidos.

Tabela 3 - Taxas de escolarização líquida (TEL) no Brasil, por grupos de idade

\begin{tabular}{lcccc}
\hline & 1995 & 1997 & 1999 & 2001 \\
\hline TEL (7 a 14 anos) & $90,2 \%$ & $93,0 \%$ & $95,7 \%$ & $96,5 \%$ \\
TEL (7 a 10 anos) & $91,7 \%$ & $93,8 \%$ & $96,5 \%$ & $97,2 \%$ \\
TEL (11 a 14 anos) & $88,7 \%$ & $92,3 \%$ & $94,9 \%$ & $95,7 \%$ \\
TEL (15 a 17 anos) & $66,6 \%$ & $73,3 \%$ & $78,5 \%$ & $81,1 \%$ \\
\hline
\end{tabular}

Fonte: PNAD, nos anos referidos.

O processo pelo qual os indicadores puderam melhorar ao longo do tempo relaciona-se com o maior número de jovens que avançam no ensino fundamental e atingem o ensino médio (cf. Gráfico 1). Por isso, 
pode-se dizer que a primeira parte do ensino fundamental é a parcela da educação brasileira mais estável nos últimos anos em termos de demanda por expansão. Em contrapartida, tem sido grande a pressão relacionada à expansão nos níveis ulteriores da educação, o que se articula com a mudança no próprio perfil social da população que recentemente passou a completar o ensino fundamental e a atingir o ensino médio. A despeito da maior pressão relativa exercida sobre os níveis mais elevados da educação básica, dois indicadores de eficiência e de qualidade do sistema educacional indicam problemas particularmente graves na primeira metade do ensino fundamental. Refiro-me à taxa de repetência ao longo da educação básica e à evolução temporal da proficiência média na $4^{a}$ série do ensino fundamental.

\section{Gráfico 1 - Evolução da matrícula}

na $3^{\text {a }}$ série do ensino médio, no Brasil

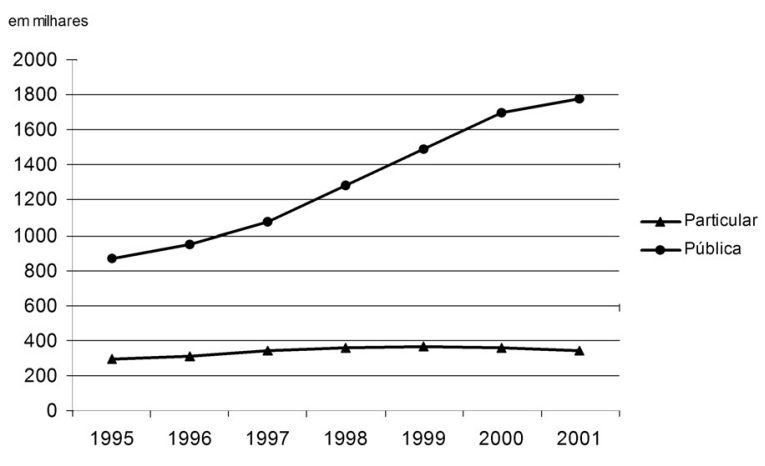

Fonte: Base de dados INEP/SAEB.

O Gráfico 2 apresenta a evolução da taxa de repetência no ensino fundamental ao longo do tempo. Sua análise indica que ocorre diminuição expressiva na taxa de repetência até 1997. A partir de então há relativa estabilidade na taxa de repetência, em patamar ainda muito elevado.

A Tabela 4 complementa as informações do Gráfico 2, apresentando a taxa de repetência no ano de 2001 para cada série da educação básica. A comparação da taxa de reprovação nos três segmentos da educação básica, ilustrados na Tabela 4, indica que o problema da repetência é particularmente grave nas séries iniciais do ensino fundamental.
Gráfico 2 - Evolução da taxa de repetência no ensino fundamental

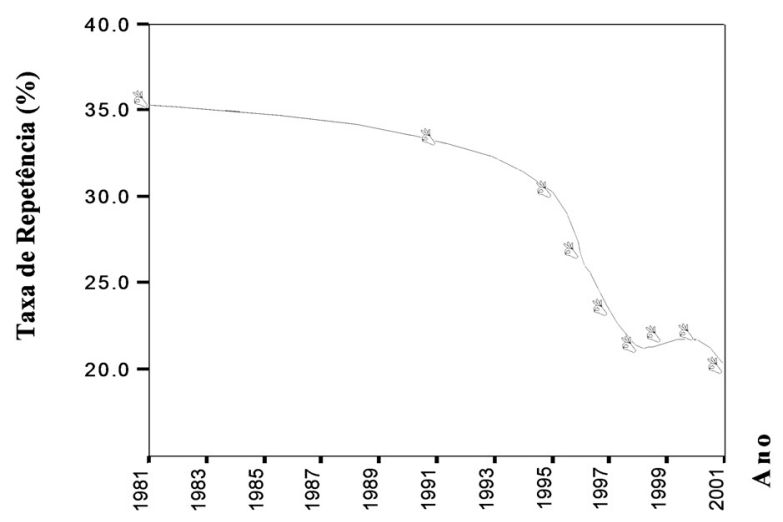

Fonte: Base de dados INEP/SAEB.

Tabela 4 - Taxa de repetência na educação básica brasileira em 2001

\begin{tabular}{|c|c|c|c|c|}
\hline \multirow{2}{*}{$\begin{array}{l}\text { Segmento } \\
\text { Ensino fundamental, } 1^{\text {a }} \text { parte }\end{array}$} & \multicolumn{4}{|c|}{ Série e Percentual de Repetência } \\
\hline & $1^{\mathrm{a}}, 32 \%$ & $2^{\mathrm{a}}, 20 \%$ & $3^{a}, 17 \%$ & $4^{\mathrm{a}}, 14 \%$ \\
\hline Ensino fundamental, $2^{\mathrm{a}}$ parte & $5^{\mathrm{a}}, 24 \%$ & $6^{\mathrm{a}}, 17 \%$ & $7^{\mathrm{a}}, 16 \%$ & $8^{a}, 15 \%$ \\
\hline Ensino médio & $1^{\mathrm{a}}, 26 \%$ & $2^{\mathrm{a}}, 19 \%$ & $3^{\mathrm{a}}, 13 \%$ & \\
\hline
\end{tabular}

Fonte: INEP, Censo Escolar.

Já o Gráfico 3 apresenta a situação relativa à evolução da proficiência em matemática na $4^{a}$ série desse ensino, evidenciando a tendência de queda da qualidade média da educação na $4^{a}$ série do ensino fundamental entre 1995 e 2001. A comparação do Gráfico 3 com o Gráfico 4 indica que a deterioração da qualidade da educação brasileira está ocorrendo nas séries iniciais, a despeito da grande expansão e da própria mudança no perfil social do ingressante do ensino médio. ${ }^{2}$ A estabilidade da proficiência média na $3^{a}$ série do ensino médio ao longo do período é um elemento bastante posi-

${ }^{2}$ Observe-se que os gráficos apresentados são baseados nos resultados em matemática, o que é plenamente compatível com a visão de letramento, que não deve ser concebido de modo restrito, unicamente relacionado com conhecimentos de língua portugue- 
tivo, especialmente quando considerada no contexto da grande expansão registrada no Gráfico $1 .^{3}$

Gráfico 3 - Evolução das médias em matemática no Brasil (4 $4^{\mathrm{a}}$ série)

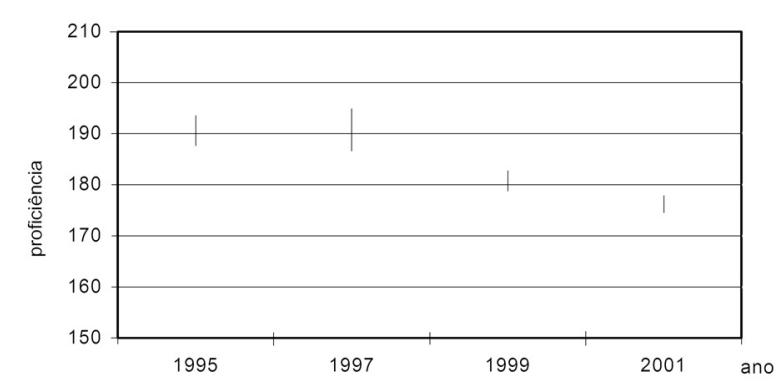

Fonte: Bases de Dados do INEP/SAEB.

Gráfico 4 - Evolução das médias em matemática Brasil (3 ${ }^{a}$ série ensino médio)

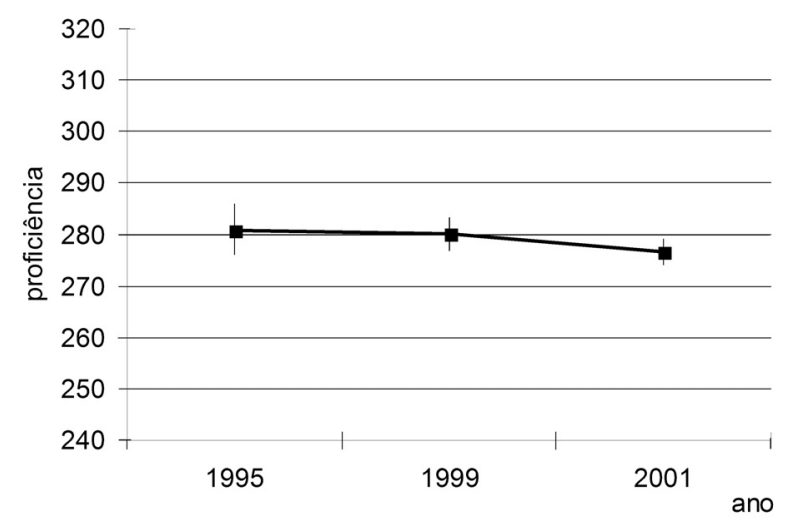

Fonte: Bases de Dados do INEP/SAEB.

sa. A opção por apresentar os gráficos de matemática foi feita porque ilustram de modo mais claro o argumento aqui desenvolvido (queda na $4^{\mathrm{a}}$ série; estabilidade na $3^{\mathrm{a}}$ série do ensino médio). Os resultados em língua portuguesa (queda em ambas as séries, embora mais acentuada na $4^{\mathrm{a}}$ série) são plenamente compatíveis com o argumento apresentado - que enfatiza a existência de problemas mais graves no início do processo de escolarização - ainda que a visualização do argumento seja menos nítida no caso de língua portuguesa do que em matemática.

${ }^{3}$ Para uma análise detalhada da evolução longitudinal de indicadores de qualidade da educação brasileira, consulte-se Franco et al. (2002).
Em síntese, as tabelas e os gráficos anteriormente apresentados enfatizam que:

a) Muito embora a taxa de repetência no ensino fundamental tenha decrescido no período considerado, faz-se necessário pontuar a tendência de estabilização da taxa, em nível ainda muito elevado, a partir de 1998 (Gráfico 2).

b) Os níveis de repetência na educação básica brasileira ainda são muito elevados para todas as séries, especialmente na primeira parte do ensino fundamental (Tabela 4).

c) Ao longo do tempo, há queda na proficiência média dos alunos que freqüentam a $4^{\mathrm{a}}$ série do ensino fundamental (Gráfico 3).

d) Ao longo do tempo, há relativa estabilidade da proficiência média dos alunos que freqüentam a $3^{\mathrm{a}}$ série do ensino médio (Gráfico 4), a despeito da grande expansão ocorrida neste nível de ensino. A comparação entre os Gráficos 3 e 4 é indicativa da importância de produção de maior e melhor conhecimento sobre a situação da etapa inicial do ensino fundamental brasileiro.

Ainda que a adesão a ciclos seja minoritária na educação brasileira, o melhor conhecimento do ensino fundamental não pode prescindir da compreensão do papel - efetivo e potencial - desta forma de organização da educação. E tal compreensão passa pelo mapeamento do estágio atual da implantação de ciclos. A próxima seção deste trabalho é dedicada a esse tema.

\section{Ciclos nas redes estaduais e nas redes municipais das capitais}

No início deste trabalho, sublinhei a inadequação de se usar a evolução do percentual de matrículas em escolas seriadas e cicladas como indicador apropriado para o acompanhamento longitudinal da evolução de adesão a ciclos, e mostrei que o uso inadequado do indicador leva a erro importante referente à tendência da políticas públicas. Ilustrei também como o uso de indicador baseado em percentual de escolas 
seriadas e cicladas oferece melhor visão de tendência. Em adendo à discussão sobre qual seja o indicador adequado para acompanhar a tendência de organização da escolarização, faz-se necessário considerar as limitações do indicador baseado em percentual de escola. Para isto, é necessário levar em conta que, na educação pública, ciclo é uma política para redes de ensino. Nesse sentido, é importante que se possa tomar também redes de ensino como unidade de análise para a construção de indicador de adesão à escolarização em séries e em ciclos. Em outras palavras: é particularmente importante conhecer quantas - e quais - redes de ensino se organizam predominantemente em ciclos ou em séries, quantas - e quais estão transitando de um modo de organização para outro e quantas - e quais - estão divididas nas duas formas de organização por conceberem que a escolha é uma atribuição da unidade escolar. Muito embora não haja nenhum levantamento sistemático e periódico que focalize diretamente as políticas das redes de ensino para a organização do ensino, é possível construir, a partir dos dados do Censo Escolar ou do questionário do SAEB, indicador da política desenvolvida pelas secretarias estaduais e municipais de educação, bastando agregar as informações levantadas nas escolas para cada rede de ensino. Ainda que este seja um procedimento bastante simples, até onde sei ainda não foi implementado com os dados disponíveis. Muito embora os dados do Censo Escolar permitam o mapeamento da situação para todo o país, neste trabalho limito-me a usar a abordagem proposta para identificar as políticas de organização da escolarização nas redes estaduais e nas redes municipais das capitais de estado. Restringir o mapeamento a este pequeno universo, sobre o qual já temos um bom conhecimento prévio da realidade, é particularmente útil para testar a potencialidade e as eventuais limitações da abordagem proposta. Futuramente, o INEP ou outros pesquisadores poderão adaptar a abordagem aqui utilizada em pequena escala para mapear o conjunto das redes públicas brasileiras e, principalmente, para acompanhar a evolução temporal das formas de organização da escolarização.
O Quadro 1 a seguir descreve a forma de organização das redes estaduais e das redes municipais das capitais a partir da agregação dos dados de 1991 . Observe-se que este quadro toma como referência a forma de organização a que estão submetidos os alunos da $4^{a}$ série do ensino fundamental ou seu correspondente no sistema de ciclos, via dados do SAEB 2001. O Quadro 1 focaliza a forma de organização predominante das redes de ensino, desprezando percentuais baixos de escolas seriadas em redes altamente cicladas, e vice-versa, mas registrou em coluna à parte a situação das redes nas quais havia presença expressiva de ambas as formas de organização.

Quadro 1 - Organização do ensino ao final do $1^{\circ}$ segmento do ensino fundamental nas redes estaduais e nas redes municipais de capitais, em 2001

\begin{tabular}{|c|c|c|c|c|}
\hline \multirow[t]{2}{*}{ Estados/Municípios } & \multirow{2}{*}{ Ciclos } & \multirow[t]{2}{*}{ Séries } & \multicolumn{2}{|c|}{ Ambos } \\
\hline & & & $\%$ Ciclos & \% Série \\
\hline Rondônia & & $\checkmark$ & & \\
\hline Acre & & $\checkmark$ & & \\
\hline Rio Branco & & $\checkmark$ & & \\
\hline Amazonas & & $\checkmark$ & & \\
\hline Manaus & & $\checkmark$ & & \\
\hline Roraima & & $\checkmark$ & & \\
\hline Pará & & $\checkmark$ & & \\
\hline Belém & $\checkmark$ & $\checkmark$ & & \\
\hline Amapá & & $\checkmark$ & & \\
\hline Macapá & & $\checkmark$ & & \\
\hline Tocantins & & $\checkmark$ & & \\
\hline Maranhão & & $\checkmark$ & & \\
\hline São Luís & & $\checkmark$ & & \\
\hline $\begin{array}{l}\text { Piauí } \\
\text { Teresina }\end{array}$ & $\checkmark$ & $\checkmark$ & & \\
\hline $\begin{array}{l}\text { Ceará } \\
\text { Fortaleza }\end{array}$ & $\checkmark$ & $\checkmark$ & & \\
\hline $\begin{array}{l}\text { Rio G. do Norte } \\
\text { Natal }\end{array}$ & $\checkmark$ & . & & \\
\hline $\begin{array}{l}\text { Paraíba } \\
\text { João Pessoa }\end{array}$ & $\checkmark$ & $\checkmark$ & & \\
\hline $\begin{array}{l}\text { Pernambuco } \\
\text { Recife }\end{array}$ & & $\checkmark$ & & \\
\hline $\begin{array}{l}\text { Alagoas } \\
\text { Maceió }\end{array}$ & $\checkmark$ & $\checkmark$ & & \\
\hline Sergipe & & $\checkmark$ & & \\
\hline Aracaju & & $\checkmark$ & & \\
\hline Bahia & & $\checkmark$ & & \\
\hline Salvador & & $\checkmark$ & & \\
\hline $\begin{array}{l}\text { Minas Gerais } \\
\text { Belo Horizonte }\end{array}$ & $\checkmark$ & & $69 \%$ & $31 \%$ \\
\hline Espírito Santo & & $\checkmark$ & & \\
\hline Vitória & & $\checkmark$ & & \\
\hline $\begin{array}{l}\text { Rio de Janeiro - RJ } \\
\text { Rio de Janeiro }\end{array}$ & $\checkmark$ & $\checkmark$ & & \\
\hline $\begin{array}{l}\text { São Paulo - SP } \\
\text { São Paulo }\end{array}$ & $\checkmark$ & & & \\
\hline $\begin{array}{l}\text { Paraná } \\
\text { Curitiba }\end{array}$ & $\checkmark$ & & $61 \%$ & $39 \%$ \\
\hline Santa Catarina & & $\checkmark$ & & \\
\hline Florianópolis & & $\checkmark$ & & \\
\hline $\begin{array}{l}\text { Rio G. do Sul } \\
\text { Porto Alegre }\end{array}$ & $\checkmark$ & $\checkmark$ & & \\
\hline $\begin{array}{l}\text { M. Grosso do Sul } \\
\text { Campo Grande }\end{array}$ & $\checkmark$ & $\checkmark$ & & \\
\hline Mato Grosso & $\checkmark$ & $\checkmark$ & & \\
\hline Goiás & & $\checkmark$ & $21 \%$ & $79 \%$ \\
\hline Distrito Federal & & $\checkmark$ & & \\
\hline
\end{tabular}


No Quadro 1, os seguintes aspectos merecem destaque: ${ }^{4}$

a) a predominância da organização em séries;

b) a organização em ciclos ocorre mais freqüentemente em redes municipais de capitais do que em redes estaduais;

c) em contrapartida, duas grandes redes estaduais São Paulo e Rio de Janeiro - organizam-se em ciclos e outra grande rede estadual - Minas Gerais - organiza-se majoritariamente em ciclos;

d) em três redes públicas havia importante presença concomitante das duas formas de organização do ensino. Por meio de informações complementares pode ser afirmado que a rede de ensino municipal de Goiânia, em 2001, estava em processo de transição para a organização em três ciclos, cada um com duração de três anos; que a rede pública do estado de Minas Gerais delegava a decisão sobre a forma de organização às unidades escolares (Fernandes \& Franco, 2001); e que a rede estadual do Paraná passava por um duplo processo de mudança, envolvendo, por um lado, transição para organização em ciclo, e por outro lado, municipalização (o que fazia com que as escolas municipalizadas precisassem, posteriormente, ajustar-se às políticas municipais de organização do ensino).

Há estados e municípios nos quais o ensino é seriado na $4^{\mathrm{a}}$ série, havendo ciclo apenas nos dois ou três primeiros anos do ensino fundamental. Este é o caso dos municípios do Rio de Janeiro e de Vitória, o que pode ser esclarecido por meio de consulta complementar aos dados do Censo Escolar.

Um complemento importante ao mapeamento da presença de ciclos seria a descrição do número e du-

${ }^{4}$ Porto Velho e Palmas não estão incluídos no Quadro 1 porque o plano amostral do SAEB 2001 não incluía estratos exclusivos para escolas municipais nessas cidades, ainda que pudessem ser amostradas. ração dos ciclos. Infelizmente, essa descrição tornase impossível diante do mau funcionamento da pergunta que aborda este tema. Em universo pequeno como o aqui apresentado, isso poderia ser facilmente equacionado por consulta às secretarias de educação. No entanto, o exercício aqui praticado objetiva principalmente ilustrar uma abordagem que possa ser usada nacionalmente, visando ao mapeamento geral da forma de organização do ensino. Por isso, recomenda-se o aprimoramento das perguntas referentes ao número e à duração de ciclos.

\section{Ciclos, condições de ensino e níveis de letramento}

O uso mais corriqueiro dos dados do SAEB envolve o monitoramento do percentual de alunos nos diversos níveis de proficiência. Já no presente trabalho, os dados do SAEB 2001 foram usados para mapear a situação da organização da escolarização. A partir da identificação do modo pelo qual as escolas amostradas pelo SAEB organizam a escolarização, outras possibilidades de investigação se abrem. Esta seção dedica-se a uma revisão de dois importantes estudos que exploraram o tema da relação entre ciclos e outras variáveis importantes mensuradas pelo SAEB 2001.

O primeiro estudo foi desenvolvido por Fernandes (2003) e, dentre outros temas, focalizou a comparação entre o contexto social, as condições escolares e as concepções de docentes que trabalhavam em escolas organizadas em séries e em ciclos. Fernandes mostrou que ciclos foram implementados em contextos sociais particularmente difíceis, marcados, por exemplo, pela preexistência de mais violência do que nos contextos onde ciclos não foram usados ou foram menos implementados. A mesma autora mostrou ainda que as escolas organizadas em ciclos freqüentemente conviviam com maiores dificuldades relacionadas às condições de ensino presentes na escola do que as escolas organizadas em séries. A maior dificuldade de condições nas escolas cicladas incluíam as relativas a recursos particularmente relevantes para os propósitos mais inerentemente ligados à concepção pedagógica de ciclos, como é o caso da estabilidade do qua- 
dro docente das escolas. Apesar disso, ainda segundo Fernandes, professores que atuavam em escolas organizadas em ciclos mostravam-se mais dispostos a correr ricos e a responsabilizarem-se pela aprendizagem de seus alunos do que professores atuantes em escolas organizadas em séries.

O estudo de Ferrão, Beltrão e Santos (2002) explorou as repercussões da forma de organização da escola sobre a proficiência em leitura e matemática dos alunos. A esta altura, o leitor já tem noção das enormes dificuldades que os autores enfrentaram. Por exemplo: como ciclo é política de rede e há inúmeras diferenças de recursos e cultura entre diferentes redes, as demandas sobre o controle estatístico necessário para responder validamente à pergunta sobre qual é o efeito da forma de organização do ensino na proficiência em leitura e matemática dos alunos da $4^{\mathrm{a}}$ série são, tipicamente, mais rigorosas do que os dados disponíveis permitem implementar. No entanto, os problemas de controle estatístico são menores nos estados em que a grande rede estadual está dividida em série $e$ ciclos. No trabalho de Ferrão, Beltrão e Santos, os resultados referentes a Minas Gerais e Paraná indicam não haver diferença estatisticamente significativa entre a proficiência na $4^{\mathrm{a}}$ série e a forma de organização em séries ou em ciclos. ${ }^{5}$

\section{Conclusões}

Nos pontos a seguir, repasso os principais resultados já apresentados e adendo comentários a eles, à guisa de conclusões.

a) O acompanhamento da evolução temporal da adesão à organização da escolarização em séries e em ciclos não deve ser feito a partir da comparação do número de matrículas em escolas seriadas e cicladas, sob pena de subestimação da efetiva adesão à organização em ciclos. As unidades de análise adequadas para o

\footnotetext{
${ }^{5}$ Com pequenas nuances, os resultados para outras regiões e estados são similares aos de Minas Gerais.
}

acompanhamento longitudinal são o percentual de escolas e, principalmente, o percentual de redes de ensino. Após o monitoramento da evolução da organização do ensino com os indicadores adequados, é oportuno contabilizar a matrícula em cada tipo de organização, de modo que mensure em termos de número de alunos o tamanho relativo da matrícula em séries e em ciclos. Mas continua sendo incorreto usar a evolução da matrícula como indicador da evolução da adesão a séries ou a ciclos.

b) Durante o período 1999-2002 o percentual de escolas organizadas em séries e ciclos sofreu alteração muito pequena, no sentido do aumento da organização em ciclos. Infelizmente, não há dados adequados para a mensuração da organização do ensino no período anterior a 1999, mas sabe-se que o grande aumento da organização em ciclo ocorreu no período imediatamente anterior ao mencionado.

c) A organização em série é amplamente majoritária no ensino fundamental (cerca de $90 \%$ das escolas e $80 \%$ das matrículas).

d) A partir de 1998, a taxa de reprovação no ensino fundamental brasileiro ficou praticamente estabilizada, em patamar extremamente elevado. No período imediatamente anterior, a taxa de reprovação diminuiu expressivamente.

e) A decomposição da taxa global de reprovação em taxas de reprovação por série indica que o problema da reprovação é geral, ao longo de toda a educação básica, ainda que o problema seja particularmente grave na parte inicial do ensino fundamental. A especial gravidade neste segmento do ensino decorre tanto do fato de que os percentuais de reprovação são mais altos no mencionado segmento quanto da evidência de que a defasagem idade-série, provocada pela repetência, é fator de risco adicional para fracasso escolar.

f) Além do problema com a eficiência na parte inicial do ensino fundamental, apontada acima, é neste segmento do ensino que se concentra o maior problema com a deterioração da quali- 
dade. Caso o problema com a qualidade não seja rapidamente revertido, ele tenderá a, rapidamente, estender-se para os níveis superiores da educação básica.

g) A evidência disponível não referenda a aflição de políticos e de setores da sociedade que tendem a associar ciclos à deterioração da qualidade. Primeiramente, porque a organização da escolarização em ciclos tem dimensão ainda muito pequena para fazer a diferença, para melhor ou para pior, no Brasil como um todo. Em segundo lugar, porque a deterioração da qualidade havida na $4^{a}$ série não se concentrou na parte do sistema educacional organizado em ciclos. Em terceiro lugar, porque a pesquisa que procurou mensurar diretamente o efeito da organização da escolarização sobre a proficiência (Ferrão, Beltrão \& Santos, 2002) - que precisa ser considerada com cautela, diante das enormes limitações nos dados disponíveis -, não referenda a associação entre forma de organização e queda de proficiência. Finalmente, porque a pesquisa que procurou mapear o contexto social das escolas organizadas em ciclos (Fernandes, 2003) indica que escolas cicladas foram implantadas em contextos sociais particularmente complicados e com deficiências expressivas, até mesmo em relação a recursos diretamente ligados à concepção de educação inerente a ciclos, como é o caso da estabilidade de equipes docentes.

h) Por fim, cumpre registrar que o trabalho implementou satisfatoriamente abordagem capaz de mapear a organização da escolarização em série e ciclos tomando como unidade de análise as redes de ensino. Essa abordagem, aqui restrita às redes estaduais e dos municípios sede de capitais, pode ser facilmente usada para mapear o Brasil como um todo.

CRESO FRANCO, doutor em educação pela Universidade de Reading (Inglaterra), é professor associado do Departamento de Educação da PUC-Rio. Seus interesses de pesquisa incluem avaliação da educação e do ensino de ciências. Organizou o livro Avalia- ção, ciclos e promoção na educação, publicado pela Artmed em 2001. Com apoio do CNPq, desenvolve projeto de pesquisa sobre qualidade e eqüidade em educação.

\section{Referências bibliográficas}

BARRETTO, E. S. S., MITRULIS, E., (2001). Trajetória e desafios dos ciclos escolares no país. Revista de Estudos Avançados, São Paulo, USP, v. 15, nº 42, p. 105-142.

BRASIL, Ministério da Educação, (2002). SAEB 2001: Relatório Nacional. Brasília: INEP - Instituto Nacional de Estudos e Pesquisas Educacionais Anísio Teixeira.

FERNANDES, C., ( 2000). Promoção automática na década de 1950 - uma revisão bibliográfica. Revista Brasileira de Estudos Pedagógicos, v. 81, nº 197, p. 76-88, jan.-abr. (2003). A escolaridade em ciclos no Brasil: uma transição para a escola do século XXI. Tese de doutorado, Departamento de Educação da Pontifícia Universidade Católica do Rio de Janeiro.

FERNANDES, C., FRANCO, C., (2001). Séries ou ciclos? O que acontece quando os professores escolhem? In: FRANCO, C. (org.). Avaliação, ciclos e promoção na educação. Porto Alegre: Artmed, p. 55-68.

FERRÃO, M.E., BELTRÃO, K., SANTOS, D., (2002). Impacto das políticas de não-repetência no desempenho acadêmico dos alunos da $4^{a}$ série: modelagem multinível. Relatório de pesquisa. Rio de Janeiro: Departamento de Educação da Pontifícia Universidade Católica do Rio de Janeiro.

FRANCO, C., MANDARINO, M., ORTIGÃO, I., ALBERNAZ, A., COIMBRA, C., (2002). Avaliação longitudinal da educação brasileira. Relatório de pesquisa. Rio de Janeiro: Laboratório de Avaliação da Educação da PUC-Rio e Fundação Getúlio Vargas.

MAINARDES, J. A, (2001). Organização da escolaridade em ciclos: ainda um desafio aos sistemas de ensino. In: FRANCO, C. (org.). Avaliação, ciclos e promoção na educação. Porto Alegre: Artmed, p. 34-54.

SOUSA, S. Z., ALAVARSE, O. M., (2003). Avaliação nos ciclos: a centralidade da avaliação. In: FREITAS, L. C. de (org.). Questões em avaliação educacional. Campinas: Komedi, p. 67-92.

Recebido em outubro de 2003 Aprovado em novembro de 2003 